\title{
The Fine Structure of Nuclei during Spermiogenesis in the Lizard Tropidurus torquatus (Lacertilia) ${ }^{1}$
}

\author{
Maria Alice da Cruz Höfling and Carminda da Cruz Landim² \\ Departamento de Morfologia, Instituto de Biologia, Unicamp, \\ 13100 Campinas S. P., Brasil
}

Received May 27, 1976

In the nucleus of most animals, the spermatozoa are a tightly compacted mass of nucleoprotein which includes the entire haploid genome of the organism. It seems likely that the structure of the chromatin of the mature sperm is different from that typical of somatic nuclei, not only by the condensation, but also for a very regular arrangement of its components (Wilkins and Randall 1953, Inoué and Sato 1962; MacInnes and Uretz 1968, Walker 1971, Macgregor and Walker 1973). This state is achieved through a process of differentiation which varies from species to species and involves, on several cases, the most extensive transformations in chromatin structure (Gall and Bjork 1958, Dass and Ris 1958, Kaye and McMasterKaye 1966, Kaye 1969, Silveira 1970, Yasuzumi 1974, Cruz-Landim and Ferreira 1975). In most vertebrates nuclear differentiation is accomplished without the appearance of special structure (Burgos and Fawcett 1955, Stanley 1969, Zirkin 1971), but in reptiles, Clark (1967) described modifications similar to those found in invertebrates.

What follows is a report of the ultrastructure of a lizard spermatid nuclei during differentiation.

\section{Material and methods}

Specimens of Tropidurus torquatus were collected and small pieces of testis were fixed in cold $3 \%$ glutaraldehyde in $0.2 \mathrm{M}$ sodium cacodylate buffer, pH 7.2 for 2 hours, followed by a 15 minutes rinse in fresh $0.2 \mathrm{M}$ buffer solution and postfixed in $1 \% \mathrm{OsO}_{4}$ in the same buffer for 1 hour. Tissues were then dehydrated in a graded ethyl alcohol series, followed by propylene oxide and then embedded in Epon 812. Sections cut on a Porter-Blum MT-2 Ultramicrotome with glass knives were stained in uranyl acetate and Reynolds lead citrate. Sections were examined and photographed with a Zeiss EM 9-S2.

The thickness of nuclear chromatin in each stage of condensation was measured with magnifying lens with a ruler inside, on 3 prints of each stage. On each print,

1 Supported by Fundação de Amparo ã Pesquisa do Estado de São Paulo (proc. Biol. 75/ 0221).

2 Departamento de Morfologia, Fac. Fil., Ciências e Letras de Rio Claro, 13500 Rio Claro, S. P., Brasil.

This work is presented at XXVII Annual Meeting of SBPC (Belo Horizonte, M. G., Brasil, 1975). 

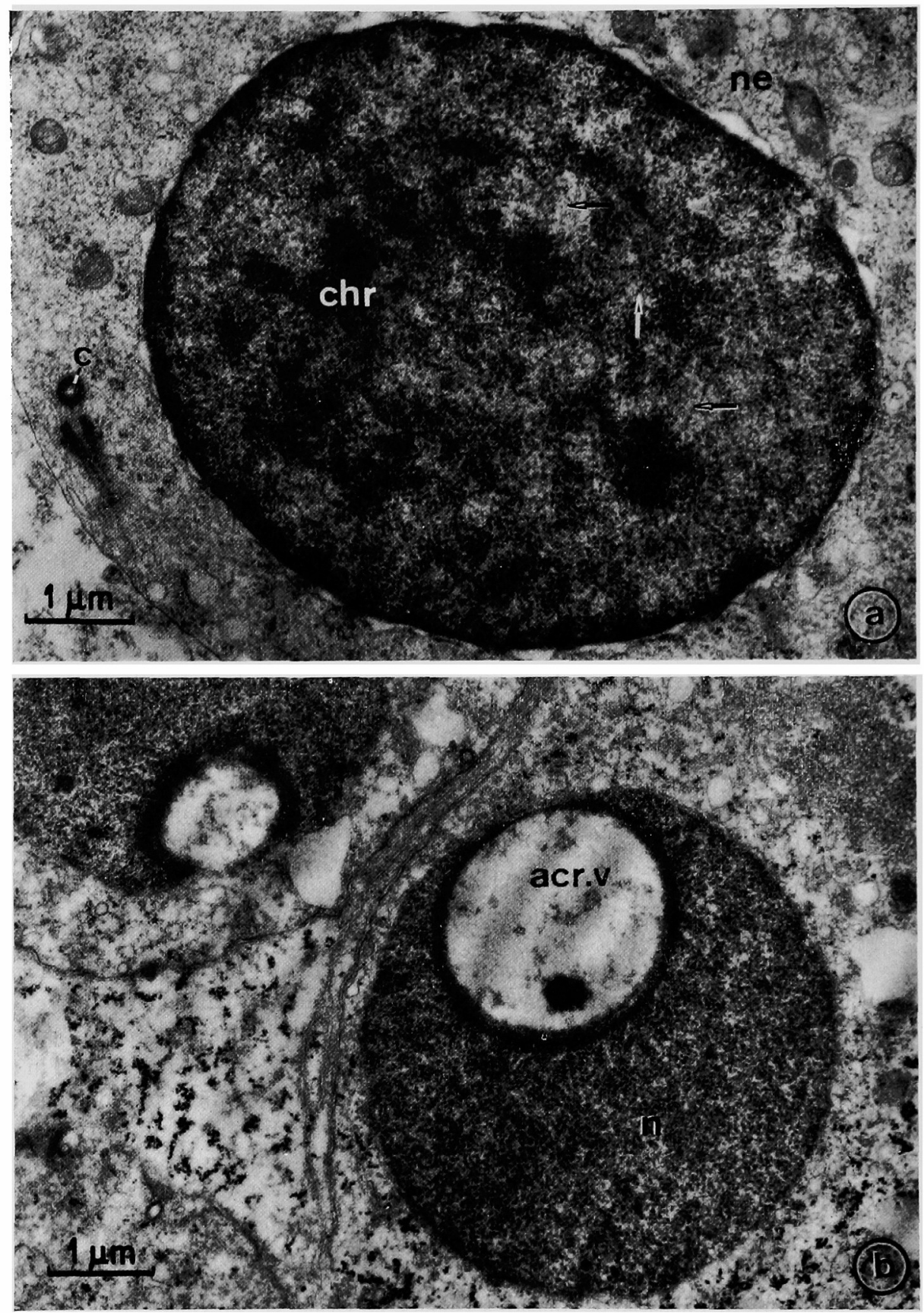

Fig. 1. a, early spermatid in which the nuclear content is distributed similar to that in somatic cells. The arrows point to chromatin (chr) fibers sectioned longitudinally. b, nuclear contents of stage I, homogeneously distributed. The acrosomal vesicle (acrv) is apparently within the nucleus (n), (c) centriole, (ne) nuclear envelope. 

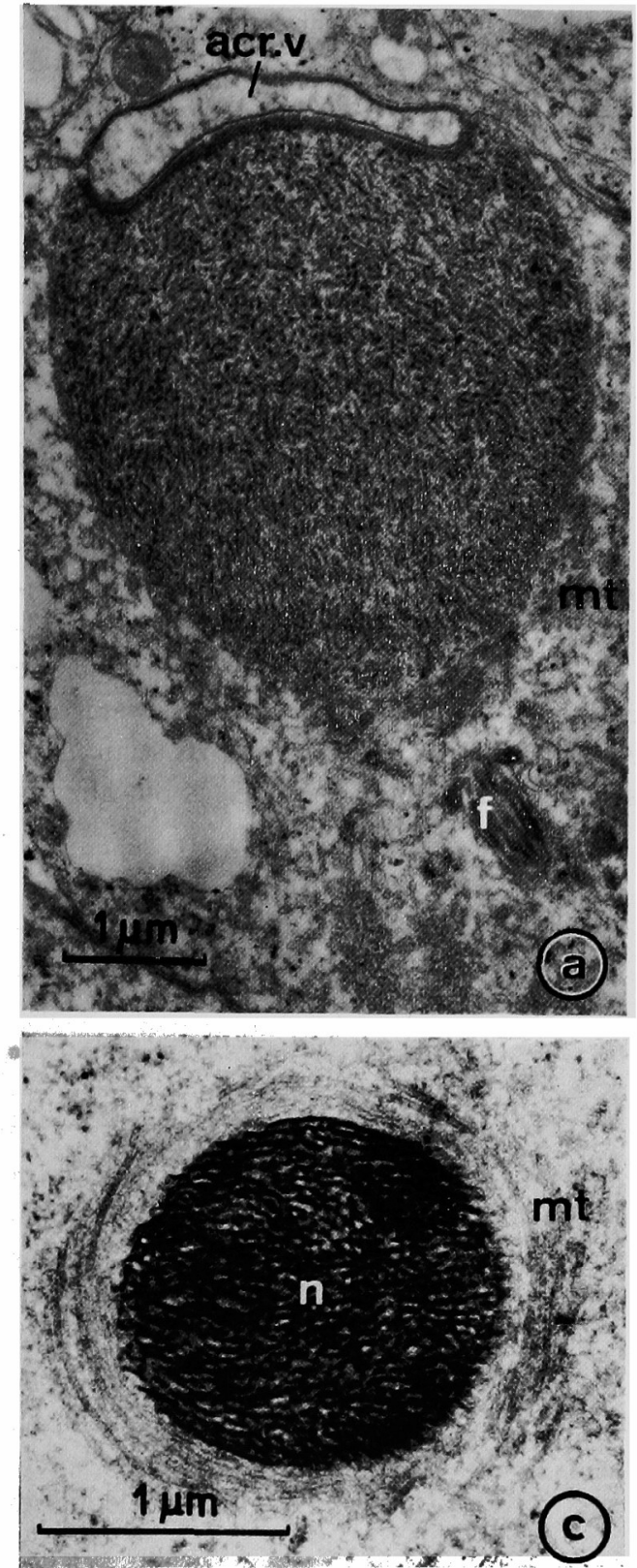

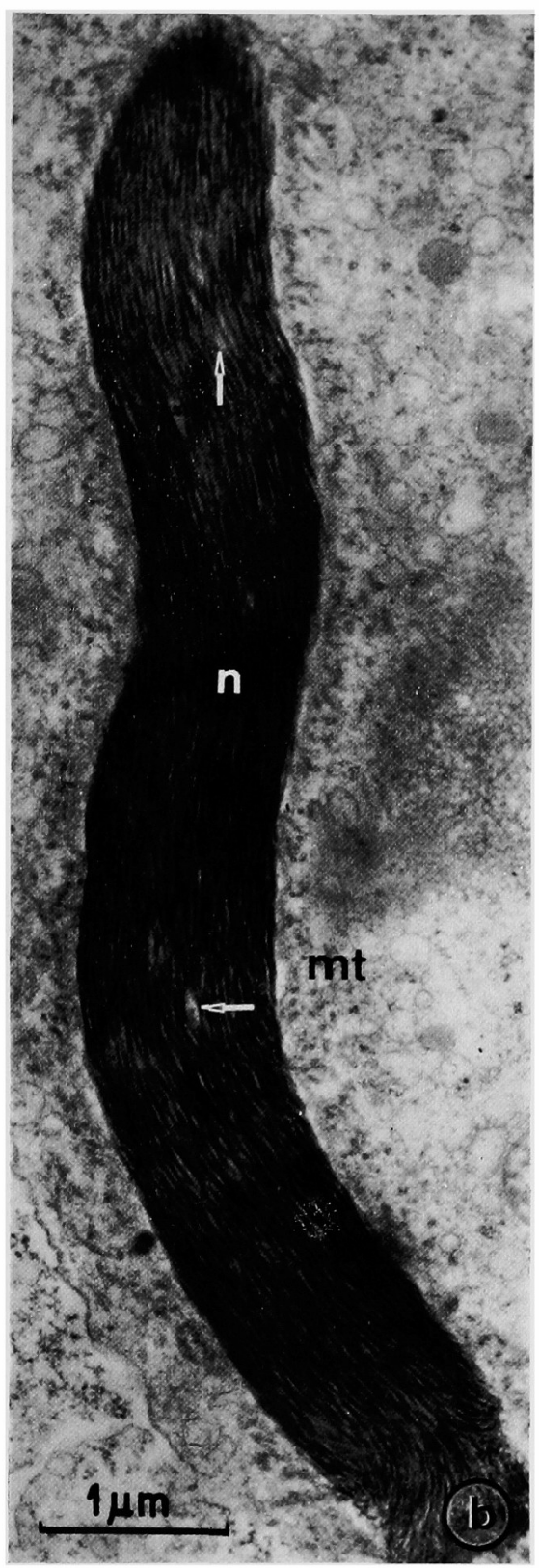

Fig. 2. a, stage II. The fibrillar nature of chromatin is now well seen. The nucleus begins to elongate. b, elongated nucleus from stage III in longitudinal section showing the screw shape and the chromatin arrangement. The arrows point to nucleoplasm zones. c, cross section of a nucleus in stage III showing the microtubules $(\mathrm{mt})$ arrangement. $\quad(\mathrm{f}=$ flagellum). 
10 chromatin fibers were measured at random. The prints were enlarged to a final magnification of approximately 60,000 times.

\section{Results}

The nucleus of an early spermatid has the chromatin in a dispersed phase showing some areas of lesser electron density where it is more diffuse (Fig. 1a). At low magnification it is apparently formed by fine granules, but at higher magnification some fibers are also detectable. The condensed and diffused chromatins seem to have same pattern of organization, and size of components. The amorphous nucleoplasm occurs among the chromatin (Fig. la).

Four stages of nuclear condensation were arbitrarily determined. The earliest stage is characterized by a round nuclei, but smaller than the preceding one and containing the acrosomal vesicle engulfed in one pole (Fig. 1b). The content of this nucleus is diffuse and fairly homogeneous, still with granular aspect at low magnification, but the dots already presenting greater size than before (Table 1). Proceeding in the differentiation, the nucleus of stage II, initiates the elongation and the acrosomal vesicle appears as a flat cisterna in its top. Now dots and lines are very evident (Fig. 2a), permiting to interpret them as longitudinal and cross sections of very contorted fibers, yet randomly distributed throughout the nucleus but already thicker (Table 1).

Table 1. Measurments of diameters of nuclear fibers

\begin{tabular}{ccc}
\hline Stage & Mean in $\mathrm{nm}$ & Range in $\mathrm{nm}$ \\
\hline Stage I & 23.1 & $12.0-31.0$ \\
Stage II & 24.3 & $16.0-31.0$ \\
Stage III & 25.2 & $15.0-33.0$ \\
Stage IV & 26.0 & $17.0-35.0$ \\
\hline
\end{tabular}

A striking reorganization of nuclear material occurs in stage III. Nuclei are characterized by a screw shape and very elongated form and by presenting the chromatin fibers in a highly organized disposition. The fibers are parallel to the nucleus length and are arranged in helicoidal course (Fig. 2b). The shape of the nucleus seems to depend upon the chromatin arrangement more than upon the microtubular manchette since the microtubules have also helicoidal course (Fig. $2 b$ and c). The alignment of the fibers forms sheaths that are disposed concentrically (Fig. 3a and b). The fibers have some points where they appose very closely and zones where they remain apart. These zones are probably occupied by the remnant nucleoplasm (Fig. 3a and b).

The condensation in stage IV shows very thicker and straight fibers which are closely packed almost without any nucleoplasm among them (Fig. $4 a$ and b). The maximum of condensation occurs when all nucleoplasm is eliminated (Fig. 4c).

\section{Discussion}

Changes in the basic protein complement have long been considered a likely 


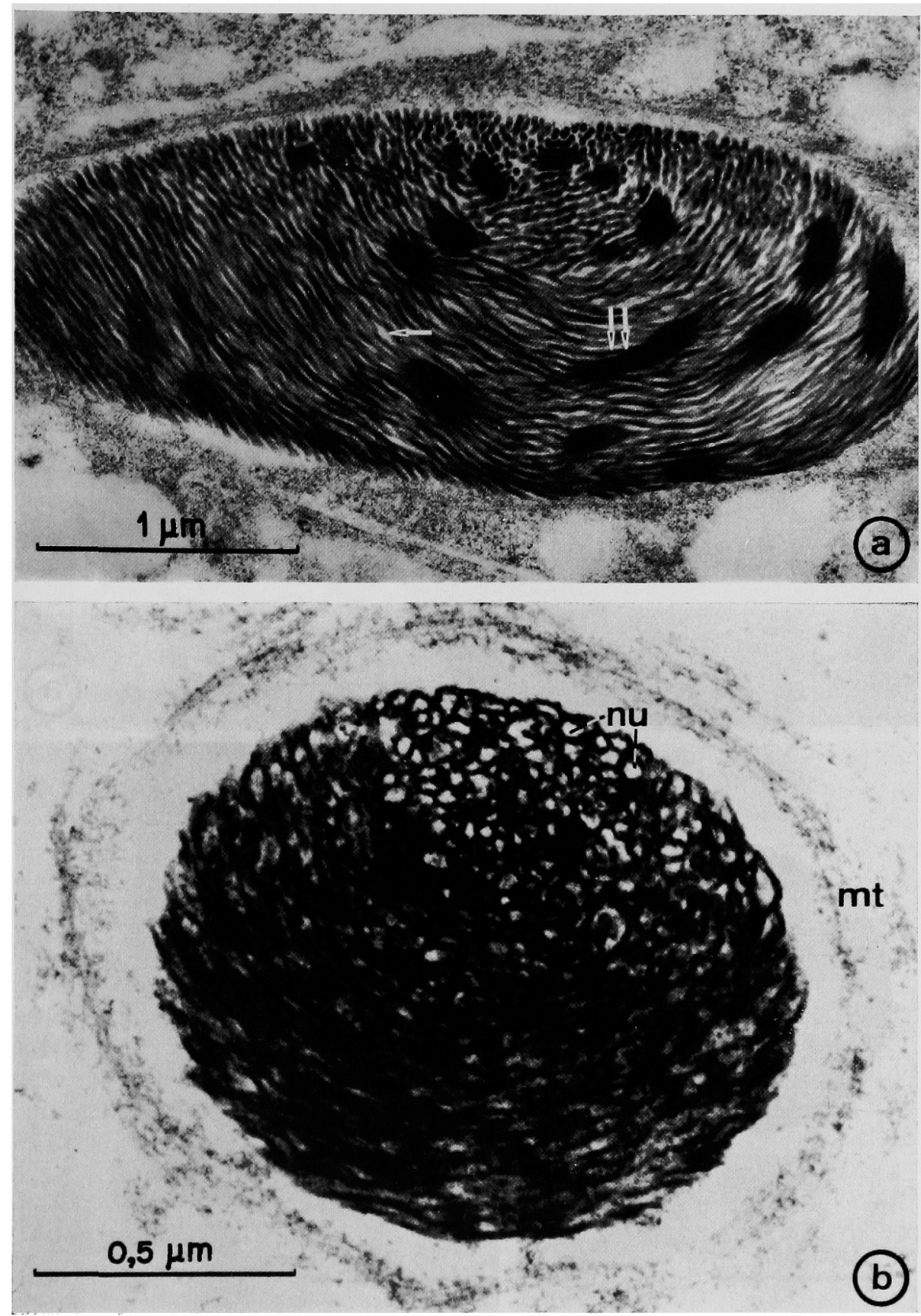

Fig. 3. a, slanting section of a nucleus in late stage III showing the points where the chromatin fibers coalesce (double arrows, and the interstitial nucleoplasm (single arrows). b, cross section of a nucleus in late stage III showing the concentric arrangement of the chromatin sheaths. $\quad(\mathrm{nu}=$ nucleoplasm). 

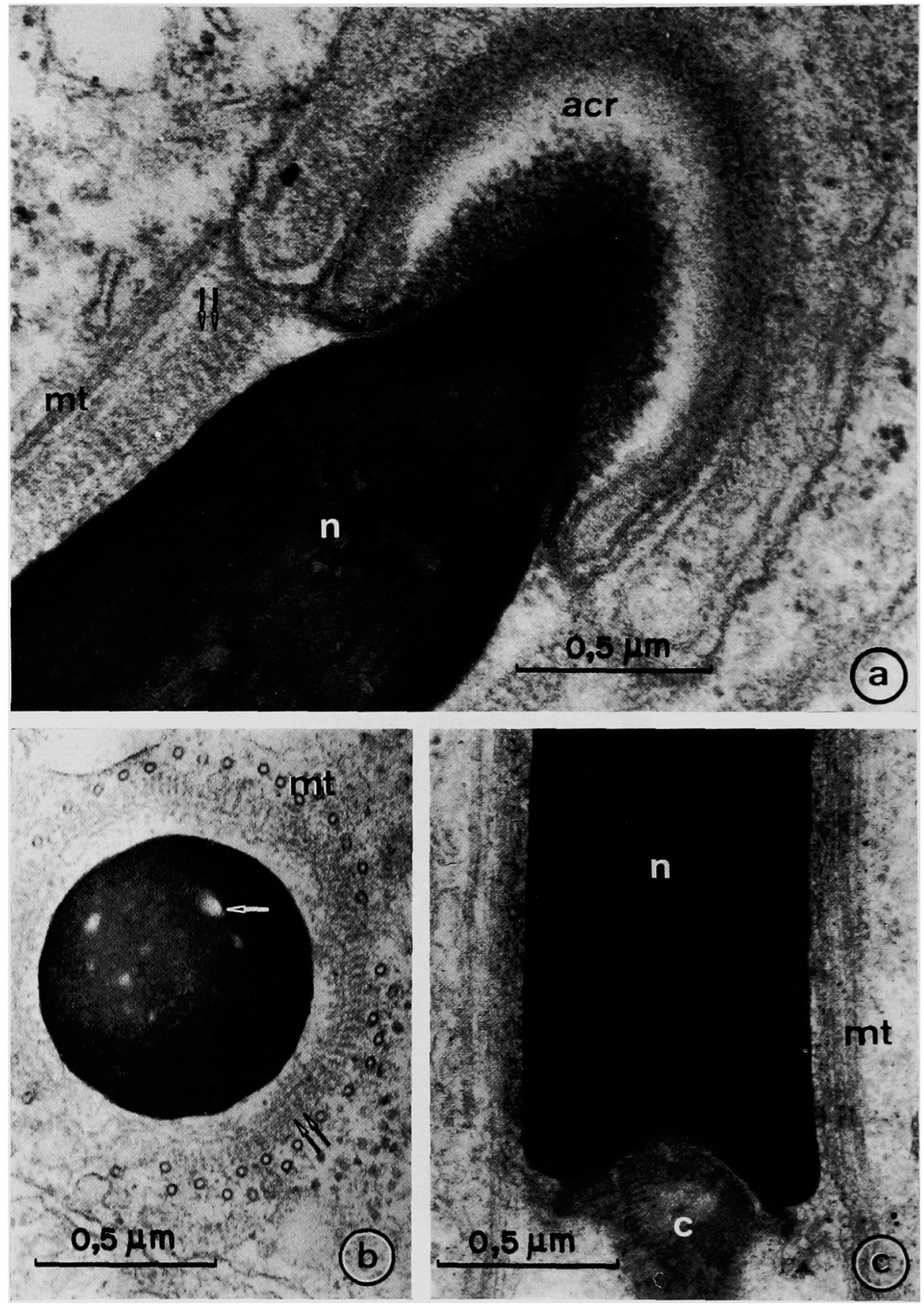

Fig. 4. a, longitudinal section of a nucleus from stage IV, from where the nucleoplasm is practically absent. b, cross sections where some areas not entirely condensed (single arrows), containing nucleoplasm, is still shown. The double arrows in $a$ and $b$ refer to saturations in the nuclear envelope (acr =acrosome). $\mathrm{c}$, in a mature spermatozoon the nucleus is composed entirely of condensed material. 
basis for the variations in chromatin structure (Alfert 1956, Bloch and Hew 1960 , Lam and Bruce 1971, Tessier and Pallota 1973, Kaye and McMaster-Kaye 1974). Histones apparently behave as non specific repressors at transcriptional level, maintaining the genes turned off. During the animal spermiogenesis the somatic-type histones are replaced by gamete-type histones or protamines (Bloch 1966) and this leads to the belief that the appearance of the gamete-type chromatin is in some way related to this transition. It has been also assumed that the process of chromatincondensation results from a dehydration of the nucleoprotein and nucleoplasm elimination (Yasuzumi 1974).

It seems obvious that there are at least two distinct phenomena involved in the nucleus maturation during the spermatogenesis: the condensation of the chromatin and its structural modifications. The condensation must result from the elimination of certain nuclear components including water and nonhistone proteins. As pointed out by Kaye and McMaster-Kaye (1966), these losses occur without detectable change in the structure of chromatin fibers. The changes in structure are related to changes in chemical composition, mainly in histone protein composition. In cases where changes in histone do not occur during spermiogenesis as in sea urchin (Kaye 1969); sand crab (Vaughn and Thomson 1972) and leopard frog (Zirkin 1971), the structural modifications do not occur although the condensation takes place.

The final form of the nucleus in the sperm cell depends upon all these modifications and at least during differentiation the shapes assumed by chromatin seem to have a role in its shaping (Rattner 1972). In the present case, the nucleus in stage III, presents a screw shape due to the chromatin organization. This form is lost with the complete maturation when the chromatin fibers straight out.

Abstract

The structure of chromatin during spermiogenesis of a lizard was examined. The fibrillar nature of chromatin is maintained during all time even in the mature sperm, but the fibers pass through a process of thickening and reorganization which begins with a homogeneous and diffuse aspect, going through an organization of chromatin fibers parallel to the long axis of the nucleus, disposed concentrically but not evenly displaced. In a final stage the fibers are thicker and closely packed showing almost no nucleoplasm among them.

\section{Acknowledgements}

The authors wish to thank Dr. Anneliese Wernick (Dept. de Fisiologia e Zoologia) by providing for the lizards.

\section{Literature cited}

Alfert, M. 1956. Chemical differentiation of nuclear proteins during spermatogenesis in the salmon. J. Biophys. Biochem. Cytol. 2: 109-114. 
Bloch, D. P. 1966. Histone differentiation and nuclear activity. Chromosoma 19: 317-339.

- and Hew, H. Y. C. 1960 . Changes in nuclear histones during fertilization and early embryonic development in the pulmonate snail Helix aspersa. J. Biophys. Biochem. Cytol. 8: 69-81.

Burgos, M. H. and Fawcett, D. W. 1955. Studies on the fine structure of the mammalian testis. I. Differentiation of spermatids of the cat (Felis domestica). J. Biophys. Biochem. Cytol. 1: $287-300$.

Clark, A. W. 1967. Some aspects of spermiogenesis in a lizard. Am. J. Anat. 121: 369-399.

Cruz-Landim, C. and Ferreira, A. 1976. Aspectos ultraestruturais da diferenciaçao nuclear durante a espermatogênese de Myogryllus sp. (Orthoptera). Rev. Brasil. Biol. 36(3): 561567.

Dass, C. M. S. and Ris, H. 1958. Submicroscopic organization of the nucleus during spermiogenesis in the grasshopper. J. Biophys. Biochem. Cytol. 4: 129-132.

Gall, J. G. and Bjork, L. B. 1958. The spermatid nucleus in two species of grasshopper. J. Biophys. Biochem. Cytol. 4: 479-484.

Inoué, S. and Sato, H. 1962. Arrangement of DNA in living sperm: biophysical analysis. Science 136: $1122-1124$.

Kaye, J. S. 1969. The ultrastructure of chromatin in nuclei of interphase cells and in spermatids. In: Handbook of Molecular Cytology. A. Lima-de-Faria, ed. North-Holland Publishing Co., Amsterdam, pp. 362-380.

- and McMaster-Kaye, R. 1966. The fine structure and chemical composition of nuclei during spermiogenesis in the house cricket 1 . Initial stages of differentiation and the loss of nonhistone protein. J. Cell Biol. 31: 159-179.

— and - 1974. Histones of spermatogenous cells in the house cricket. Chromosoma 46: 397419.

Lam, D. M. K. and Bruce, W. R. 1971. The biosynthesis of protamine during spermatogenesis of the mouse: extraction, partial characterization and site of synthesis. J. Cell Physiol. $78: 13-24$.

Macgregor, H. C. and Walker, M. H. 1973. The arrangement of chromosomes in nuclei of sperm from Plethodontid salamanders. Chromosoma 40;243-262.

MacInnes, J. W. and Uretz, R. B. 1968. DNA organization in the mature sperm of several Orthoptera by the method of polarized fluorescence microscopy. J. Cell Biol. 38: 426-436.

Rattner, J. B. 1972. Nuclear shaping in marsupial spermatids. J. Ultrastruct. Res. 40: 498-512.

Silveira, M. 1970. Characterization of an unusual nucleus by electron microscopy. J. Submicr. Cytol. 2: 13-24.

Stanley, H. P. 1969. An electron microscope study of spermiogenesis in the teleost fish Oligocottus maculosus. J. Ultrastruct. Res. 27: 230-243.

Tessier, A, and Pallotta, D. 1973. Analysis of basic proteins during spermatogenesis in the cricket Achaeta domestica. Exp. Cell Res. 82: 103-110.

Vaughn, J. C. and Thomson, L. A. 1972. A kinetic study of DNA and basic protein metabolism during spermatogenesis in the sand crab, Emerita analoga. J. Cell Biol. 52: 322-337.

Walker, M. H. 1971. Studies on the arrangement of nucleoprotein in elongate sperm heads, Chromosoma 34: 340-354.

Wilkins, M. H. F. and Randall, J. T. 1953. Crystallinity in sperm heads, molecular structure of nucleoprotein in vivo. Biochim. Biophys. Acta (Amst.) 10: 192-193.

Yasuzumi, G. 1974. Electron microscope studies on spermiogenesis in various animal species. Int. Rev. Cytol. 37: 53-119.

Zirkin, B. R. 1971. The fine structure of nuclei during spermiogenesis in the leopard frog Rana pipiens. J. Ultrastruct, Res. 34: 159-174. 